\title{
PENGEMBANGAN APLIKASI KONSULTASI DAN PENGUKURAN STATUS GIZI USIA REMAJA (SMA) SECARA ONLINE (NUTRI-O)
}

\author{
Dodhi Widyatnoko*, Meiwita Budiharsana², Artha Prabawa ${ }^{3}$ \\ * Informatika Kesehatan, Program Studi Magister Ilmu Kesehatan Masyaakat, \\ Fakultas Kesehatan Masyarakat, Universitas Indonesia, Depok 16424 \\ 2-3 Department Biostatistics dan Kependudukan, Fakultas Kesehatan \\ Masyarakat, Universitas Indoensia, Depok \\ e-mail: dodhiwidyatnoko@gmail.com \\ DOI : https://doi.org/10.35451/jkg.v2i2.390
}

\begin{abstract}
ABSTRAK
In Indonesia, the current trends and issues has changed of the malnutrition paradigm. The nutritional status of adolescents in Indonesia is experiencing double burden problems (Riskesdas 2007, 2010, and 2013). This happens due to improper lifestyle and eating habits, thus causing adolescents to be at risk of malnutrition, both deficiency or overnutrition. The nutrient deficiency has an impact on decreasing physical abilities, immune system, thinking and learning concentration. While overnutrition such as overweight and obesity in adolescents, increasing the risk of non-infectious diseases during adulthood such as heart and blood vessel disease, high blood pressure, dyslipidemia, and diabetes mellitus. The purpose of this study is to develop an Android-based m-Health application model as an effort to monitor nutritional status and online consultation. The development method that used is a prototype. Application modeling begins with system requirements analysis, context diagrams, Entity Relational Diagrams (ERD), Table Relational Diagrams (TRD), Flow Charts and User Interface Design. Adolescent nutritional status measured base on Height divided by Age (TB / U), Body Mass Index divided by Age (BMI / U) and other health conditions. The system information formed by the design concept can provide an information of nutritional status and fascinate competent nutritionists to give an interactive nutritional consultation.
\end{abstract}

Keywords: online monitoring nutritional status. online nutritional consultation. m-health 


\section{PENDAhUlUAN}

Hasil Riskesdas pada tahun 2018 menunjukan bahwa prevalensi remaja dengan status gizi kurus secara nasional sebesar $6,7 \%$ sedangkan prevalensi dengan status gizi lebih atau gemuk sebesar 9,5\%. Hal ini memilik arti, Indonesia saat ini sedang mengalami masalah gizi ganda (double burden) pada kelompok usia remaja.

Remaja adalah transisi dari anakanak menuju ke dewasa. Masa ini merupakan masa terpenting di dalam kehidupan. Di masa ini, terjadi pertumbuhan maupun perubahan biologis diantaranya pematangan seksual, peningkatan berat dan tinggi badan. (Almatsier, 2013). Proses pertumbuhan dan perkembangan masa remaja memerlukan asupan zat gizi dalam jumlah cukup dan seimbang antara asupan gizi yang masuk ke dalam tubuh dengan kecukupan gizi yang yang diperlukan.

Menurut Brown J dkk dalam Yusintha A.N (2018), Perubahan bentuk dan ukuran tubuh menyebabkan remaja memiliki citra tubuh dan gangguan makan sehingga rentan akan permasalah gizi. Kurangnya pengetahuan remaja tentang perilaku makan yang sehat juga menyebabkan remaja cenderung memiliki perilaku makan salah. Umumnya prilaku remaja, cenderung hanya memilih makanan yang disukainya. (Preedy V.R: 2011).

Salah satu upaya yang dapat dilakukan untuk mengatasi masalah gizi remaja adalah melakukan pemberian informasi dan pendidikan gizi melalui kegiatan konseling gizi. (Mahmudiono T dan D.N Chintya Ade, 2013). Namun, permasalah selanjutnya adalah kegiatan konseling gizi umumnya masih dilakukan secara konvensional atau berupa pertemuan secara langsung antara klien dan konselor. Hal ini dirasa kurang sesuai bagi remaja berkaitan dengan waktu dan karakteristik sikap kurang terbuka jika berhadapan langsung.

Menurut Hakim S.N, dkk (2017), pada era digital saat ini pengguna internet dan teknologi gadget yang tinggi adalah kelompok remaja usia Sekolah Menengah Atas (SMA). Hal ini dapat dijadikan peluang yang baik untuk melakukan terobosan inovasi bidang kesehatan khususnya dalam hal pemantauan status gizi dan pemberian konseling gizi pada remaja SMA. Melihat masalah dan peluang yang ada, dirasa perlu ada pengembangan aplikasi mobile health berbasis android untuk melakukan pemantauan status gizi dan konseling gizi secara online bagi remaja usia SMA.

\section{METODE}

Metode pengembangan sistem yang digunakan dalam penelitian ini menggunakan pendekatan konsep system development life cycle (SDLC) dengan model prototype, dimana prototype merupakan pengembangan sistem yang melalui serangkaian pengulangan proses untuk memasukkan perubahan yang dibutuhkan sampai sistem memenuhi kriteria yang diinginkan ${ }^{7}$, dalam tulisan ini metode prototype hanya sampai tahap pemodelan aplikasi. Pemodelan aplikasi diawali dengan analisis kebutuhan kemudian perancangan sistem. Perancangan sistem meliputi pembuatan diagram konteks, Entity Relational Diagrams (ERD), Table Relational Diagrams (TRD), dan Flow Charts. Pengukuran status gizi remaja usia SMA yang digunakan berdasarkan Tinggi Badan dibagi Umur (TB/U) dan Indek Masa Tubuh dibagi Umur (IMT/U). (WHO, 2006). 
3. HASIL DAN PEMBAHASAN

A. Analisis kebutuhan sistem

Berdasarkan studi pustaka dan observasi yang dilakukan, didapat kebutuhan sistem yang sesuai dengan tujuan dan fungsi dari aplikasi adalah sebagai berikut:

Tabel 1 Rekap kebutuhan sistem

\begin{tabular}{lll}
\hline Tahap & $\begin{array}{c}\text { Situasi saat } \\
\text { ini }\end{array}$ & Kebutuhan \\
\hline Input & 1. & Kurangnya \\
pemantau & 1. & $\begin{array}{l}\text { Perlu ada } \\
\text { sistem }\end{array}$ \\
& an status & \multicolumn{1}{c}{ untuk } \\
gizi & memantau \\
& dikalangan & status gizi \\
& remaja & remaja \\
& SMA & 2. Perlu \\
& 2. Kesulitan & sebuah \\
& pada & media yang \\
& remaja & menyediak \\
& untuk & an \\
& mendapat & informasi \\
& kan & dan \\
infromasi & konsultasi \\
dan & terkait \\
& berkonsult & status gizi \\
& asi terkait & pada \\
& status gizi & remaja
\end{tabular}

secara

personal

3. Karakterist

ik remaja

yang ingin

praktis,

cepat dan

bersosial.

\begin{tabular}{|c|c|c|}
\hline Proses & $\begin{array}{l}\text { Kurangnya } \\
\text { informasi dan } \\
\text { komunikasi } \\
\text { antara } \\
\text { remaja, orang } \\
\text { tua, pihak } \\
\text { sekolah dan } \\
\text { petugas } \\
\text { kesehatan } \\
\text { terkait } \\
\text { permasalahan }\end{array}$ & $\begin{array}{l}\text { Pengembanga } \\
\mathrm{n} \text { sistem } \\
\text { konsultasi dan } \\
\text { monitoring } \\
\text { status gizi } \\
\text { yang } \\
\text { memanfaatka } \\
\text { n teknologi } \\
\text { internet, } \\
\text { sebagai upaya } \\
\text { pendekatan }\end{array}$ \\
\hline & $\begin{array}{ll}\text { gizi } & \text { yang } \\
\text { dialami } & \text { oleh } \\
\text { remaja } & \end{array}$ & $\begin{array}{l}\text { yang sesuai } \\
\text { dengan } \\
\text { karakteristik } \\
\text { remaja. }\end{array}$ \\
\hline cisput & $\begin{array}{l}\text { Pemantaua } \\
\text { n status gizi } \\
\text { remaja dan } \\
\text { konsultasi }\end{array}$ & $\begin{array}{l}\text { 1. Aplikasi } \\
\text { yang dapat } \\
\text { menyediak } \\
\text { an }\end{array}$ \\
\hline
\end{tabular}

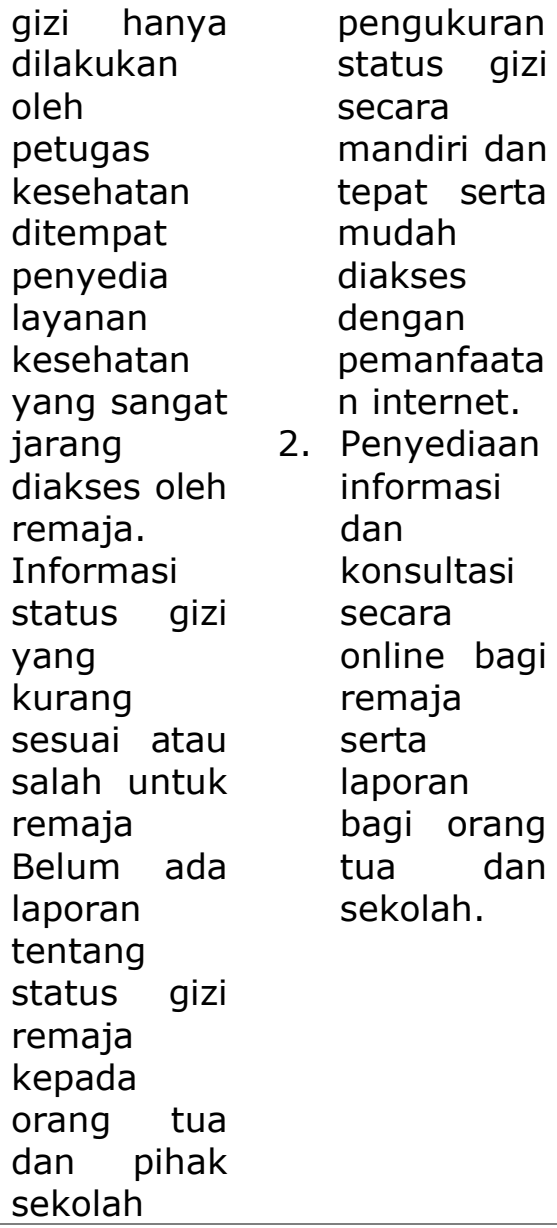

\section{B. Perancangan sistem}

Analisis kebutuhan sistem yang diperoleh selanjutnya menjadi acuan dalam proses perancangan sistem. Perancangan sistem umumnya memuat desain diagram konteks, Entity Relational Diagrams (ERD), Table Relational Diagrams (TRD), dan Flow Charts. (Sommerville I: 2011).

I. Diagram konteks

Secara garis besar diagram konteks sistem ini dibagi menjadi dua entitas yaitu entitas input dan entitas output, entitas input antara lain remaja, ahli gizi dan admin. Sementara entitas output adalah orang tua remaja dan pihak sekolah (guru) terkait. 


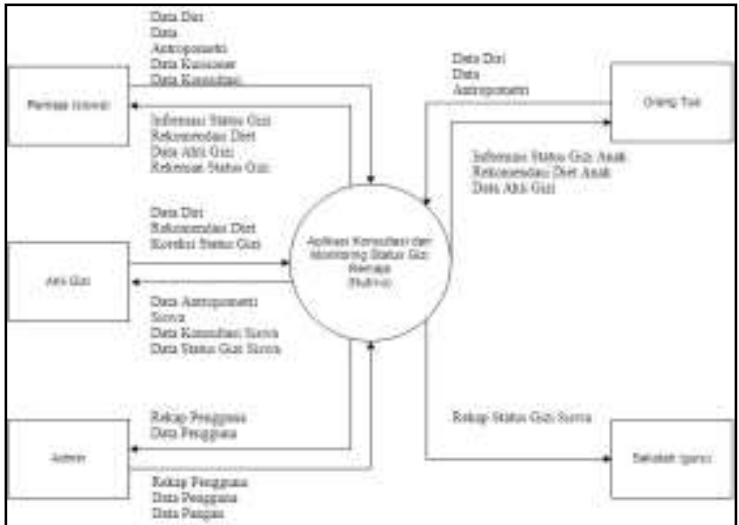

Gambar 1 Diagram konteks Nutri-O Diagram konteks menggambarkan aliran data dari setiap entitas yang terlibat. Pada gambar tersebut terlihat terdapat entitas yang hanya mendapat informasi dari aplikasi tanpa memasukan data ke dalam aplikasi, yaitu entitas sekolah (guru).

\section{Entity Relational Diagrams (ERD)} Entitas relational diagram merupakan diagram yang menjelaskan hubungan antara entitas yang terlibat pada sistem. Pada setiap entitas memiliki atribut dan primary key.

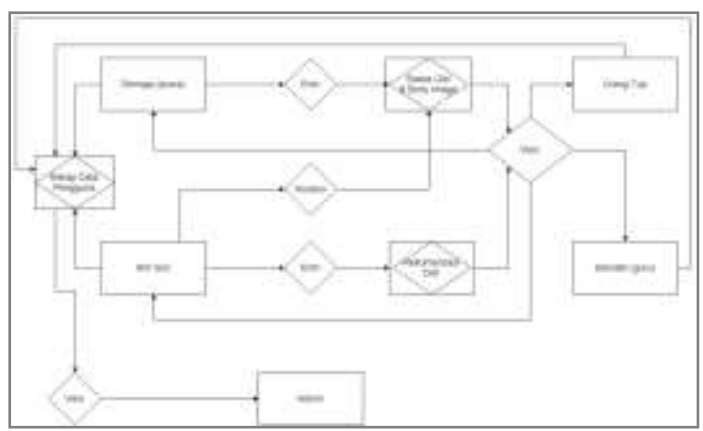

Gambar 2 Entity Relational Diagrams Atribut merupakan jenis data yang dimilik oleh suatu entitas, sedangkan primaty key merupakan salah satu jenis data yang bersifat unik bagi suatu entitas. Bagan hubungan entitas pada aplikasi yang dikembangkan, dapat dilihat pada gambar diatas.

III. Table Relational Diagrams (TRD)

Diagram hubungan tabel menggambarkan hubungan antara atribut yang terdapat pada setiap entitas berdasarkan keseuaian dengan primary key. TRD bertujuan sebagai dasar skema proses yang terdapat pada sistem database. Berikut gambaran TRD dari aplikasi:

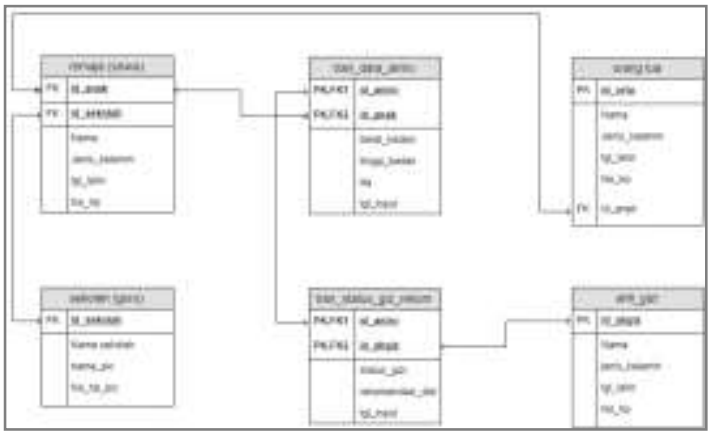

Gambar 3 Table Relational Diagrams Tabel yang ada merupakan data yang diperlukan oleh sistem untuk menjalankan proses. Hubungan antar tabel menggambarkan proses yang berjalan pada sistem, dimana siswa memasukan data antropometri kemudian sistem akan menampilkan hasil perhitungan status gizi, selanjutnya akan diteruskan ke ahli gizi, orang tua serta pihak sekolah.

IV. Flow Chart

Gambaran prosedur proses yang berjalan pada aplikasi dapat dilihat dari diagram alir berikut:

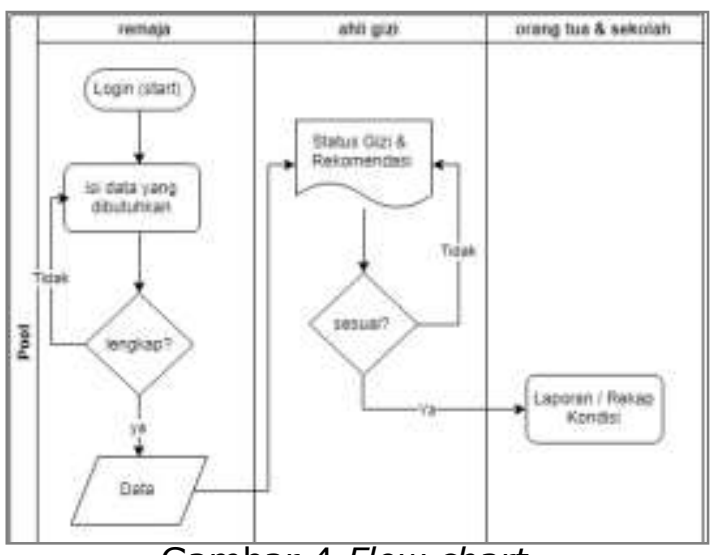

Gambar 4 Flow chart

Pada gambar tersebut berfungsi untuk memperlihatkan pihak (entitas) yang terlibat berdasarkan prosedur yang perlu dijalankan oleh pihak yang terlibat pada sistem. 
Received: 04 April 2020 :: Accepted: 23 April 2020 :: Published: 30 April 2020

\section{KESIMPULAN}

Pengembangan Aplikasi m-health sebagai upaya konsultasi dan pengukuran status gizi bagi usia remaja ini, masih dalam tahap pemodelan prototyping. Perlu dilakukan wawancara mendalam dengan pengguna dan observasi lebih lanjut untuk menghasilkan sebuah aplikasi yang lebih memenuhi kebutuhan. Kesederhanaan penggunaan bahasa agar lebih mudah dipahami oleh kalangan remaja, belum masuk dalam perancangan sistem. Aplikasi ini diharapkan dapat digunakan oleh tenaga ahli gizi dan diterapkan di Sekolah Menengah Atas, agar memudahkan pemantauan dan konseling masalah gizi pada remaja serta meningkatkan kepedulian remaja, orang tua, dan sekolah akan pentingnya status gizi pada usia remaja.

\section{DAFTAR PUSTAKA}

Almatsier, S. 2013. Prinsip dasar Ilmu Gizi. Jakarta: Gramedia Pustaka Utama.

Depkes RI. 2018, Laporan Hasil Riset Kesehatan Dasar (Riskesdas) tahun 2018, Badan Penelitian dan Pengembangan Kesehatan Kementerian RI tahun 2018. http://www.depkes.go.id/resources/ download/infoterkini/materi_rakorp op_2018/Hasil\%20Riskesdas\%2020 18.pdf-Diakses Desember 2019.

Everett GD and McLeod R. Software Testing: Testing Across the Entire
Software Development Life Cycle. 2006. Epub ahead of print 2006. DOI: $10.1002 / 9780470146354$.

Hakim S.N, Raj Alyu A, Prastiwi Chita F.D. 2017. Remaja dan Internet. Prosiding Seminar Nasional "Penguatan Individu di Era Revolusi Informasi". Fakultas Psikologi Universitas Muhammadiyah Surakarta.

Mahmudiono T dan D.N Chintya Ade. 2013. Hubungan Pola Makan, Aktivitas Fisik, Sikap, Dan Pengetahuan Tentang Obesitas Dengan status Gizi Pegawai Negeri Sipil di Kantor Dinas Kesehatan Provinsi Jawa Timur. Surabaya: Universitas Airlangga.

Preedy VR. 2011. Handbook of Behavior, Food and Nutrition. London (EN): Springer.

Sommerville, Ian. 2011. Software Engineering (9th Edition). USA, Pearson Education.

WHO. 2006b. "Adolescent Nutrition: A Review of The Situation in Selected South-East Asian Countries" New Delhi: Regional Office of South-East Asia, World Health Organisation Page. 3-29.

Yusintha A.N dan Adriyanto. 2018. Hubungan Antara Perilaku Makan dan Citra Tubuh dengan Status Gizi Remaja Putri Usia 15-18 tahun. Surabaya: Fakultas Kesehatan Masyarakat, Universitas Airlangga. http://dx.doi.org/10.20473/amnt.v2 i2.2018.147-154. 